\title{
EFFECT OF CALCINATION ON THE ELECTRICAL PROPERTIES AND QUANTUM CONFINEMENT OF $\mathrm{Fe}_{2} \mathrm{O}_{3}$ NANOPARTICLES
}

\author{
S. I. Srikrishna Ramya ${ }^{1}$, C. K. Mahadevan ${ }^{2}$ \\ ${ }^{I}$ Physics Research Centre, S. T. Hindu College, M.S.University, Nagercoil - 629 002, Tamilnadu, India \\ ${ }^{2}$ Physics Research Centre, S. T. Hindu College, M.S.University, Nagercoil - 629 002, Tamilnadu, India
}

\begin{abstract}
$\mathrm{Fe}_{2} \mathrm{O}_{3}$ nanoparticles have been prepared by a simple solvothermal method using a domestic microwave oven. X-ray powder diffraction measurement indicates the amorphous nature of the as-prepared sample. Calcined samples were obtained by annealing the as-prepared sample at different temperatures, viz. 400, 500, 600 and $700^{\circ} \mathrm{C}$. Transmission electron microscopic images indicate that all the five samples are spherical in shape. AC electrical measurements were carried out on pelletized samples by the parallel plate capacitor method at various temperatures ranging from $40-130^{\circ} \mathrm{C}$ and frequencies ranging from $100 \mathrm{~Hz}-1 \mathrm{MHz}$. Results indicate low AC electrical conductivities and consequently show the occurrence of nano confined states. The exciton Bohr radii obtained from the dielectric constant values at $40^{\circ} \mathrm{C}$ temperature and $1 \mathrm{kHz}$ frequency are 41.8, 54.8, 55.3, 56.3 and 27.0 respectively for the asprepared sample and samples calcined at 400, 500, 600 and $700^{\circ} \mathrm{C}$ which indicate a strong quantum confinement effect. The impedance spectra observed exhibit non-ideal behavior.
\end{abstract}

Keywords: Semiconductors, Magnetic materials, Nanoparticles, Electrical properties $* * *$

\section{INTRODUCTION}

$\mathrm{FeO}, \mathrm{Fe}_{2} \mathrm{O}_{3}$ and $\mathrm{Fe}_{3} \mathrm{O}_{4}$ are the three main types of iron oxide nanoparticles. They are considered to be important materials due to their biocompatibility, catalytic activity, non-toxicity, low-cost and environmentally friendly nature. In applications like solar energy transformation, electronics, electrochemistry, manufacture of magnetic storage media, sorption and purification processes and catalysis, amorphous ferric oxide $\left(\mathrm{Fe}_{2} \mathrm{O}_{3}\right)$ plays a key role especially because of its superior catalytic activity, superparamagnetic behavior and the large specific surface area of the nanoparticles [1].

The ferric oxide has four crystallographic phases, viz. $\alpha-\mathrm{Fe}_{2} \mathrm{O}_{3}$ (hematite), $\beta-\mathrm{Fe}_{2} \mathrm{O}_{3}, \gamma-\mathrm{Fe}_{2} \mathrm{O}_{3}$ (maghemite) and $\varepsilon-\mathrm{Fe}_{2} \mathrm{O}_{3}$ [2]. Recently, we have reported [2] the preparation by a simple route and chemical, structural, optical and magnetic characterization of the four nanophases of $\mathrm{Fe}_{2} \mathrm{O}_{3}$, viz. $\gamma$ - in the amorphous condition (as-prepared) and $\alpha-, \beta$ - (slightly mixed with $\alpha-$ ), and $\varepsilon^{-}$in the crystalline state. As these nanostructured materials are also electrically important, it becomes necessary to investigate their electrical properties.

The nanoparticles often exhibit unusual electric behaviors different from that of their bulk counterparts owing to finite size effects. The interest in understanding the electrical properties of transition metal oxides is being renewed because of their potential use in the development of novel electronic devices. It has been discovered that nanoscaling of transition metal oxides can have a considerable impact on their chemical behavior, and that they can exhibit distinctive properties including high dielectric constants, efficient charge separation and chemical surface reactivity [3]. The dielectric properties of a number of oxides in their films form have been investigated for electrical applications [4-6]. Bonaedy et al [7] have investigated the magneto-dielectric property of polycrystalline $\gamma-\mathrm{Fe}_{2} \mathrm{O}_{3}$. Hasegawa et al [8] have investigated the electrical and magnetic properties of $\gamma-\mathrm{Fe}_{2} \mathrm{O}_{3}$ (001) epitaxial films. Recently, Naresh and Bhowmic [9] have observed that both magnetic softness and electrical conductivity increase with the decrease of grain size in the case of $\alpha-\mathrm{Fe}_{1.4} \mathrm{Ti}_{0.6} \mathrm{O}_{3}$.

It is known that quantum confinement effects arise when the size of the particles fall below the exciton bohr radius of the material [10]. Also, when the particle (grain) size is smaller than the electron mean free path, grain boundary scattering dominates which results in dramatic changes in electrical conductivity and polarizability, etc. [11]. The electrical property and charge confinement effect of quantum dots (QDs) can be accounted by the dielectric constant.

Although several reports are available on magnetic and other properties of $\mathrm{Fe}_{2} \mathrm{O}_{3}$ nanoparticles, reports on electrical properties are limited. Also, effect of calcinations on the electrical properties has not been reported. In the present article, we report on the AC electrical measurements carried out on $\mathrm{Fe}_{2} \mathrm{O}_{3}$ nanoparticles (prepared by a simple solvothermal method) in the frequency range $100 \mathrm{~Hz}-1 \mathrm{MHz}$ and in the temperature range $40-130^{\circ} \mathrm{C}$ with emphasis on the dependence of calcination temperature. 


\section{MATERIALS AND METHODS}

All the chemical reagents used are of Analytical Reagent (AR) grade and were used without further purification. The $\mathrm{Fe}_{2} \mathrm{O}_{3}$ nanoparticles were prepared by the simple solvothermal method using a domestic microwave oven reported previously by us [2]. Ferric chloride and urea were used as the precursors and ethylene glycol as the solvent.

$\mathrm{X}$-ray powder diffraction (PXRD) measurements were carried out using an automated diffractometer (XPERT PRO PANalytical) with $\mathrm{CuK}_{\alpha}$ radiation $(\lambda=1.54056 \AA \hat{)})$ to understand the crystallinity of the as-prepared sample. The asprepared sample was calcined at different temperatures, viz. $400,500,600$ and $700^{\circ} \mathrm{C}$ for $1 \mathrm{~h}$ in each case in air and then brought to room temperature naturally. Morphology and microstructure were recorded by using a PHILIPS Technai-10 instrument for the as-prepared and three calcined (at 400, 500 and $600^{\circ} \mathrm{C}$ ) samples and a HITACHI H-800 TEM instrument for the sample calcined at $700^{\circ} \mathrm{C}$.

The dielectric measurements (i.e. capacitance, $C_{p}$ and dielectric loss factor, $\tan \delta$ ) were made to an accuracy of $\pm 1 \%$ at nine different frequencies, viz. $100 \mathrm{~Hz}, 500 \mathrm{~Hz}, 1 \mathrm{kHz}, 5$ $\mathrm{kHz}, 10 \mathrm{kHz}, 50 \mathrm{kHz}, 100 \mathrm{kHz}, 500 \mathrm{kHz}$ and $1 \mathrm{MHz}$, and in each case, at four different temperatures, viz.40, 70, 100 and $130^{\circ} \mathrm{C}$ by the parallel plate capacitor method for the palletized samples (hydraulically pressed with a pressure of 4 tons) using an LCR meter (Agilent 4284 A) in a way similar to that adopted by Mahadevan and his co-workers [11, 12]. The dielectric parameters, viz. dielectric constant (both real and imaginary parts, viz. $\varepsilon^{\prime}$ and $\left.\varepsilon^{\prime \prime}\right)$ and $\mathrm{AC}$ electrical conductivity $\left(\sigma_{a c}\right)$ were determined using the measured $C_{p}$ and $\tan \delta$ values.

The real and imaginary parts of the dielectric constant were calculated using the following relations:

$$
\varepsilon^{\prime}=\frac{C_{p} d}{\varepsilon_{0} A}
$$

and

$$
\varepsilon^{\prime \prime}=\varepsilon^{\prime} \tan \delta
$$

Where $\varepsilon_{0}$ is the permittivity of free space and is equal to 8.854 $\mathrm{x} 10^{-12} \mathrm{~F} / \mathrm{m}, d$ is the thickness of the pellet and $A$ is the area of cross-section of the pellet. The AC conductivity of the sample was calculated using the relation:

$$
\sigma_{\mathrm{ac}}=\varepsilon^{\prime} \varepsilon_{0} \omega \tan \delta
$$

where $\omega$ is the angular frequency $(\omega=2 \pi f$ where $f$ is the frequency of the applied AC field). The impedance measurements (i.e. impedance, $Z$ and phase angle) were carried out on the pellets to an accuracy of $+1 \%$ with Agilent 4284A LCR meter in the frequency range $100 \mathrm{~Hz}-1 \mathrm{MHz}$ at four different temperatures, viz. $40,70,100$ and $130^{\circ} \mathrm{C}$ in a way similar to that adopted by Saravanan and Mahadevan [13]. The cole-cole plots were drawn by finding the real $Z\left(Z^{\prime}\right)$ and imaginary $Z\left(Z^{\prime \prime}\right)$ values from the measured $|Z|$ and phase angle values. The exciton bohr radius $\left(a_{B}\right.$ in $\mathrm{nm}$ ) was estimated by using the relation [11]:

(4)

$$
a_{B}=\frac{h^{2} \varepsilon_{r}}{4 \pi^{2} e^{2}}\left[\frac{1}{m_{e}{ }^{*}}+\frac{1}{m_{h}{ }^{*}}\right]
$$

Where $\varepsilon_{r}$ is the dielectric constant (i.e. $\varepsilon^{\prime}$ here), $m_{e}{ }^{*}$ and $m_{h}{ }^{*}$ are the effective masses of electron and hole respectively, $e$ is the electronic charge and $h$ is the Planck's constant. We have used the $\varepsilon^{\prime}$ value observed at $40^{\circ} \mathrm{C}$ temperature and $1 \mathrm{kHz}$ frequency and a value of $12.5 / \mathrm{m}_{\mathrm{o}}$ (where $m_{o}$ is the electron rest mass) [14] for the bracketed item in relation (4).

The porosity of the pellet was calculated using the relation:

$$
P=1-\frac{D_{0}}{D_{x}}
$$

Where $D_{0}$ is the apparent density of the pellet determined by assuming the cylindrical shape of the pellet and using the relation:

$$
D_{0}=\frac{m}{v}=\frac{m}{A d}
$$

Where $m$ and $v$ are mass and volume respectively of the pellet The bulk density $\left(D_{x}\right)$ was calculated using the relation:

$$
D_{x}=\frac{Z M}{N V}
$$

Where $Z$ is the number of molecules per unit cell, $M$ is the molecular weight, $N$ is the Avogadro's number and $V$ is the volume of the unit cell.

\section{RESULTS AND DISCUSSION}

Figure 1 shows the photograph of the as-prepared and calcined samples along with the corresponding pallets. The PXRD pattern of the as-prepared sample is shown in Figure 2. Figure 3 shows the transmission electron microscopic (TEM) images observed. Table 1 contains the particle (grain) sizes $(D)$ estimated through TEM analysis (reported in [2]), the bulk 
densities $\left(D_{x}\right)$, pellet densities $\left(D_{o}\right)$ and porosity percentages (P\%).

Figure 2 indicates the nearly amorphous nature of the asprepared sample. The crystallographic phases of the asprepared and calcined samples have been identified (reported in [2]) as: Amorphous $\gamma-\mathrm{Fe}_{2} \mathrm{O}_{3}$ (As-prepared), crystalline $\varepsilon$ $\mathrm{Fe}_{2} \mathrm{O}_{3}$ (Calcined at $400^{\circ} \mathrm{C}$ ), crystalline $(\varepsilon+\beta)-\mathrm{Fe}_{2} \mathrm{O}_{3}$ (Calcined at $500^{\circ} \mathrm{C}$ ), Crystalline $(\beta+\alpha)-\mathrm{Fe}_{2} \mathrm{O}_{3}$ (Calcined at $600^{\circ} \mathrm{C}$ ) and crystalline $\alpha-\mathrm{Fe}_{2} \mathrm{O}_{3}$ (Calcined at $700^{\circ} \mathrm{C}$ ). The TEM images indicate that the nanoparticles are agglomerative and spherical in shape. The morphology is found to be homogeneous (see Figure 3) and the particle size increases with the increase of calcination temperature (see Table 1).

The dielectric parameters, viz. $\varepsilon^{\prime}, \varepsilon^{\prime \prime}$, tan $\delta$ and $\sigma_{a c}$ are shown in Figures 4-7. Table 2 contains the observed $\varepsilon^{\prime}, \varepsilon^{\prime \prime}$ , tan $\delta$ and $\sigma_{a c}$ values at $40^{\circ} \mathrm{C}$ temperature and $1 \mathrm{kHz}$ frequency and the estimated $a_{B}$ values. Calcination dependences of $\varepsilon^{\prime}$, $\varepsilon^{\prime \prime}, \tan \delta$ and $\sigma_{a c}$ are illustrated in Figures 8 and 9. The $\varepsilon^{\prime}$, $\varepsilon^{\prime \prime}, \tan \delta$ values increase with the increase in temperature and decrease with the increase in frequency. This nature of variation is in agreement with that reported earlier for iron oxide thin film [4] and for other oxide dielectric films [15]. Also, this is considered to be a normal behavior. In addition, it is observed that the as-prepared and two calcined (at lower temperatures, viz. 400 and $500^{\circ} \mathrm{C}$ ) samples (structurally $\gamma$ - and $\varepsilon$ - based phases) exhibit very high temperature dependence of $\varepsilon^{\prime}, \varepsilon^{\prime \prime}$ and $\sigma_{a c}$ (see Figure 8). The temperature dependences of $\varepsilon^{\prime}, \varepsilon^{\prime \prime}$ and $\sigma_{a c}$ are less in the case of $\alpha$ - and $\beta$-based phases.

The dielectric behavior of nanostructured materials, as per the theory, is primarily due to different types of polarizations present in the material [16]. The dielectric constant is attributed to four types of polarizations [17] such as electronic, ionic, dipolar and space charge polarizations. All these four types of polarizations contribute at lower frequencies and hence the $\varepsilon^{\prime}$ and $\varepsilon^{\prime \prime}$ values are usually higher. Variation of $\varepsilon^{\prime}$ and $\varepsilon^{\prime \prime}$ with temperature is strong in the case of space charge and dipolar polarizations $[17,18]$.

The nanoparticles possess enormous number of interfaces, and the large number of defects present at these interfaces can cause a charge distribution. When an electric field is applied these space charges move and get trapped but these defects result in the formation of dipole moments. Interfaces in nanocrystals possess many oxygen ion vacancies [2] which are equivalent to positive charges giving dipole moments. When exposed to an electric field these dipoles rotate giving a resultant dipole moment in the direction of the applied field [19]. The space charge and dipolar polarizations occur upto frequencies of around $1 \mathrm{kHz}$ only. Thus, the higher dielectric constant values observed at lower frequencies can be attributed mainly to the space charge and dipolar polarizations
[20]. As the temperature increases more and more dipoles will be oriented resulting in an increase in the dipole moment value [21]. The increase of dielectric constant value with the increase of temperature observed in the present study can be explained as due to the above reason. Ionic polarization is expected to exist up to a frequency of $100 \mathrm{kHz}$. Beyond 100 $\mathrm{kHz}$ frequency, only electronic polarization can exist. The decrease of dielectric constant value with the increase of frequency observed in the present study can be explained as due to this.

The $\varepsilon^{\prime}$ values observed at $40^{\circ} \mathrm{C}$ temperature and $1 \mathrm{kHz}$ frequency are significantly less than the standard dielectric constant value (14.2) for iron oxide and that observed for thin film (12.5) [4]. This indicates that the polarization mechanism in the nanophases considered is mainly due to the space charge polarization and consequently indicates the occurrence of nanoconfined states which may substantially contribute to the electrical properties. In nanophases, the excitonic size becomes comparable or even larger than the particle which results in splitting of the energy bands into discrete quantization levels. The low $D / a_{B}$ ratios indicate a strong quantum confinement effect [11].

The $\sigma_{a c}$ values observed in the present study for all the five samples are very small (i.e. the resistances are very large). $\alpha$ $\mathrm{Fe}_{2} \mathrm{O}_{3}$, generally, has a conductivity of $10^{-1}-10^{-4} \mathrm{mho} / \mathrm{m}$ and it increases for samples doped with other metal ions [22-24]. Leygraf et al [25] have reported a conductivity of $1-10 \mathrm{mho} / \mathrm{m}$ for a Mg-doped iron oxide cathode. The electrical conductivity at room temperature for iron oxide thin film is found to be in the order of $10^{-2} \mathrm{mho} / \mathrm{m}[4,26]$. Hasegawa et al [8] have observed at room temperature a conductivity of $\sim 1$ $\mathrm{mho} / \mathrm{m}$ for the $\gamma-\mathrm{Fe}_{2} \mathrm{O}_{3}$ epitaxial films. The $\sigma_{a c}$ values observed in the present study are comparable to the DC conductivity of $10^{-6} \mathrm{mho} / \mathrm{m}$ observed [27] at room temperature for nanocrystalline $\alpha-\mathrm{Fe}_{2} \mathrm{O}_{3}$ powder with average particle size $35 \mathrm{~nm}$. The low $\sigma_{a c}$ values observed for the nanoparticles (with low particle sizes) indicate that the charge transport process is mainly due to the grain boundary scattering [28].

The electrical conductivity of nanoparticles is lower than that of both conventional coarse grained polycrystalline material and alloys. In composites, the magnitude of electrical conductivity can be changed by altering the size of the electrically conducting component. It appears to be that the particle size also plays a crucial role in the AC conductivity. It is generally accepted that smaller the particle sizes higher the lattice defects. Some reports suggest that lattice defects form acceptor- or donor-like levels in the forbidden energy gap and act as trapping centres for charge carriers which affect the electrical behavior [29]. The $\sigma_{a c}$ value, in the present study, increases with the increase in temperature but does not vary systematically with frequency especially at higher temperatures. This may be due to the randomness in the grain 
boundary scattering and trapping of charge carriers especially at higher temperatures.

The electrical charges migrate under the influence of the applied electrical field that contributes to the electrical response of the system. The conductivity is an increasing function of frequency in the case of conduction of hopping and is a decreasing function of frequency in the case of band conduction (drift of electric charge carriers). The total conductivity (depending on the absolute temperature, T) can be considered as the summation of both the band and hopping parts represented by the relation:

$$
\sigma_{\mathrm{tot}}=\sigma(\mathrm{T})+\sigma(\omega, \mathrm{T})
$$

The first term is due to the band conduction and frequency independent that can be considered as the DC conductivity [30-32]. The second term is due to the hopping process and is frequency dependent that can be considered as the AC conductivity

The AC conductivity is expected to obey the empirical formula of the frequency dependence given by the AC power Law [32]:

$$
\sigma(\omega, \mathrm{T})=\sigma_{\mathrm{ac}} \quad=\mathrm{B} \omega^{\mathrm{n}}
$$

Here, $\mathrm{B}$ and $\mathrm{n}$ are constants which depend on the both temperature and compositions; $\mathrm{n}$ is dimension less virus $\mathrm{B}$ has the electrical conductivity units $(\mathrm{mho} / \mathrm{m})$. The logarithmic representation of equation (9) can be written as;

$$
\ln \sigma_{\mathrm{ac}}=\ln \mathrm{B}+\mathrm{n}(\ln \omega)
$$

The values of $n$ and $B$ can be determined by plotting $\ln \sigma_{a c}$ against $\ln \omega$.

In the presence study, the $\sigma_{\mathrm{ac}}$ values were calculated using relation (3) depending on dielectric measurement. Figure (8) shows the $\sigma_{\mathrm{ac}}$ versus $\ln \omega$ drawn using the calculated $\sigma_{\mathrm{ac}}$ values. Equation (9) shows increasing AC conductivity with the increasing frequency. However, this behavior is not seen at high temperatures (see Figures 7 and 10). This indicates that the normal semiconducting behavior is exhibited at low temperatures for the samples considered in the present study. It is understood that the value of $\mathrm{n}$ ranges between 0 and 1 . When $\mathrm{n}=0$, the electrical conduction is frequency independent or DC conduction, but for $\mathrm{n} \geq 1$, the conduction is frequency dependent or $\mathrm{AC}$ conduction [30]. The $\mathrm{n}$ and $\mathrm{B}$ values were determined by best fitting the $\ln \sigma_{\mathrm{ac}}$ versus $\ln \omega$ lines using the least squares principles. $\mathrm{n}$ value ranges from 0.13 to 0.67 which suggests that the conduction phenomenon in the studied samples is AC conduction due to hopping of charges. Fig 11 shows the temperature dependence of B values. As B is the conductivity value when the frequency of the applied field is zero, this may be treated as the DC conductivity, $\sigma_{\mathrm{dc}}$.

It is found that the temperature dependence of $\sigma_{\mathrm{dc}}$ is higher for the As-prepared, calcined at $400^{\circ} \mathrm{C}$ and calcined at $500^{\circ} \mathrm{C}$ samples as in the case of AC conductivity. The $\sigma_{\mathrm{dc}}$ values are significantly less than $\sigma_{\mathrm{ac}}$ values as expected.

The cole-cole plots (see Figure 12) illustrate the non-ideal behavior (i.e. departure from a single arc centred on the real axis of $Z, Z^{\prime}$-axis). The non-ideal behavior exhibited by the impedance spectra can be explained as due to the presence of a high degree of defects [33] such as oxygen vacancies [2] present in the grain boundaries.

The $\varepsilon^{\prime}$ values at $1 \mathrm{kHz}$ frequency and $130^{\circ} \mathrm{C}$ temperature are 4199, 2939 and 4809 respectively for the as-prepared and calcined at $400^{\circ} \mathrm{C}$ and $500^{\circ} \mathrm{C}$ samples. This very high temperature dependence of $\varepsilon^{\prime}$ indicates that these nanoparticles can be expected to be useful for high temperature capacitor applications.

\section{CONCLUSIONS}

$\mathrm{Fe}_{2} \mathrm{O}_{3}$ nanoparticles have been prepared with spherical shape and amorphous nature by a simple solvothermal method. The as-prepared and calcined (at 400,500600 and $700^{\circ} \mathrm{C}$ ) samples have been structurally and electrically characterized by TEM analysis and dielectric measurements. TEM images indicate the spherical shape. Results of dielectric measurements indicate a strong quantum confinement effect. The non-ideal behavior exhibited by the impedance spectra could be explained as due to the oxygen vacancies present in the grain boundaries. The increase of calcinations temperature does not influence the electrical properties in a systematic way as the properties are crystal structure dependent. The very high temperature dependence of $\varepsilon_{r}$ observed for the as-prepared and calcined at 400 and $500^{\circ} \mathrm{C}$ samples indicate that they can be expected to be useful for high temperature capacitor applications.

\section{REFERENCES}

[1] L. Machla, R. Zboril, A. Gedanken, J. Phys. Chem B. 111 (2007) 4003-4018.

[2] S. I. Srikrishna Ramya, C. K. Mahadevan, Mater. Lett. 89 (2012) 111-114.

[3] N. Iordanova, M. Dupuis, K. M. Rosso, J. Chem. Phys. 122 (2005) 144305-144314.

[4] S. S. Kulkarni, C. D. Lokhand, Mater. Chem. Phys. 82 (2003) 151-156.

[5] J. A. Glasscock, P. R. F. Barnes, I. C. Plumb, A. Bendavid, P. J. Martin, Thin Solid Films. 516 (2008) 1716-1724.

[6] S. S. Shinde, R. A. Bansode, C. H. Bhosale, K. Y. Rajpure, J. Semiconductors. 32 (2011) 013001-013008. 
[7] T. Bonaedy, Y. S. Koo, K. D. Sung, J. H. Jung, Appl. Phys. Lett. 91 (2007) 132901-132903.

[8] M. Hasegawa, H. Yanagihara, Y. Toyoda, E. Kita, L. Ranno. J. Magn. Magn. Mater. 310 (2007) 2283-2285.

[9] N. Naresh, R. N. Bhowmik, J. Phys. Chem. Solids. 73 (2012) 330-337.

[10] Y. Wang, N. Herron, J. Phys. Chem. 95 (1991) 525532.

[11] R. S. S. Saravanan, D. Pukazhselvan, C. K. Mahadevan, J. Alloys. Compd. 509 (2011) 4065-4072.

[12] C. K. Mahadevan, K. Jayakumari, Physica B: Condens. Mater. 403 (2008) 3990-3996.

[13] R. S. S. Saravanan, C. K. Mahadevan, J. Alloys. Compd. 541 (2012) 115-124.

[14] M. B. Sahana, C. Sudakar, G. Setzler, A. Dixit, A. J. Thakur, G. Lawes, R. Naik, V. M. Naik, P. P. Vaishnava, Appl. Phys. Lett. 93 (2008) 23190912319093.

[15] A. Goswami, A. P. Goswami, Indian P. Appl. Phys. 12 (1974) 26-31.

[16] M. Chi-Mel, Z. Lide, W. Guozhong, Nanostrut. Mater. 6 (1995) 823-826.

[17] L. L. Hench, J. K. West, Principles of Electronic Ceramics. JohnWiley and Sons, New York, 1990.

[18] A. Verma, O. P. Thakur, C. Prakash, T. C. Goel, R. G. Mendiratta, Mater. Sci. Eng. B. 116 (2005) 1-6.

[19] J. Maier, S. Prill, B. Reichert, Solid State Ionics, 28 (1988) 1465-1469.

[20] B. Tareev, Physics of Dielectric materials. Mir Publishers, Moscow, 1979.

[21] T. Kar, R. N. Choudhary, S. Sharma, K. S. Singh, Ind. J. Phy. 73A (1999) 453.
[22] M. Anderman, J. H. Kennedy, Introduction to Semiconductor Electrodes (Eds. H.O.Finklear), Elsevier; Newyork: 1998, pp.147.

[23] C. Cai, D. Jiang, R. Tong, S. Jin, J. Zhang, Electrochim. Acta. 36 (1991) 1585-1590.

[24] K. Gurunathan, P. Maruthamuthu, Int. J. Hydrogen Energy 20 (1995) 287-295.

[25] C. Leygraf, M. Hendewerk, G. Somorjai, J. Solid State Chem. 48 (1983) 357-367.

[26] S. H. Pawar, P. S. Patil, R. D. Madhale, C. D. Lokhande, Indian J. Pure Appl. Phys. 27 (1989) 227 230.

[27] P. P. Sarangi, S. R. Vadera, M. K. Patra, C. Prakash, N. N. Ghosh, J. Am. Ceram. Soc. 92 (2009) 2425-2428.

[28] R. S. S. Saravanan, D. Pukazhselvan, C. K. Mahadevan, J. Alloys. Compd. 517 (2012) 139-148.

[29] C. Karunakaran, S. Sakthi Raadha, P. Gomathisankar, J. Alloys. Compd. 549 (2013) 269-275.

[30] M. A. El Hiti, J. Phys. D : Appl. Phys. 29 (1996) 501505 .

[31] A. M. Abo El Ata, M. K. El Nimra, S. M. Attia, D. El Kony, A. H. Al-Hammadi, J Magn Magn Mater 297 (2006) 33-43.

[32] M. Abdullah Dar, K. M. Batoo, V. Verma, W. A. Siddiqui, R. K. Kotnala, J. Alloys. Compds. 493 (2010) 553-560.

[33] L. Brus, J. Phys. Chem. 90 (1986) 2555-2560.

\section{FIGURES}

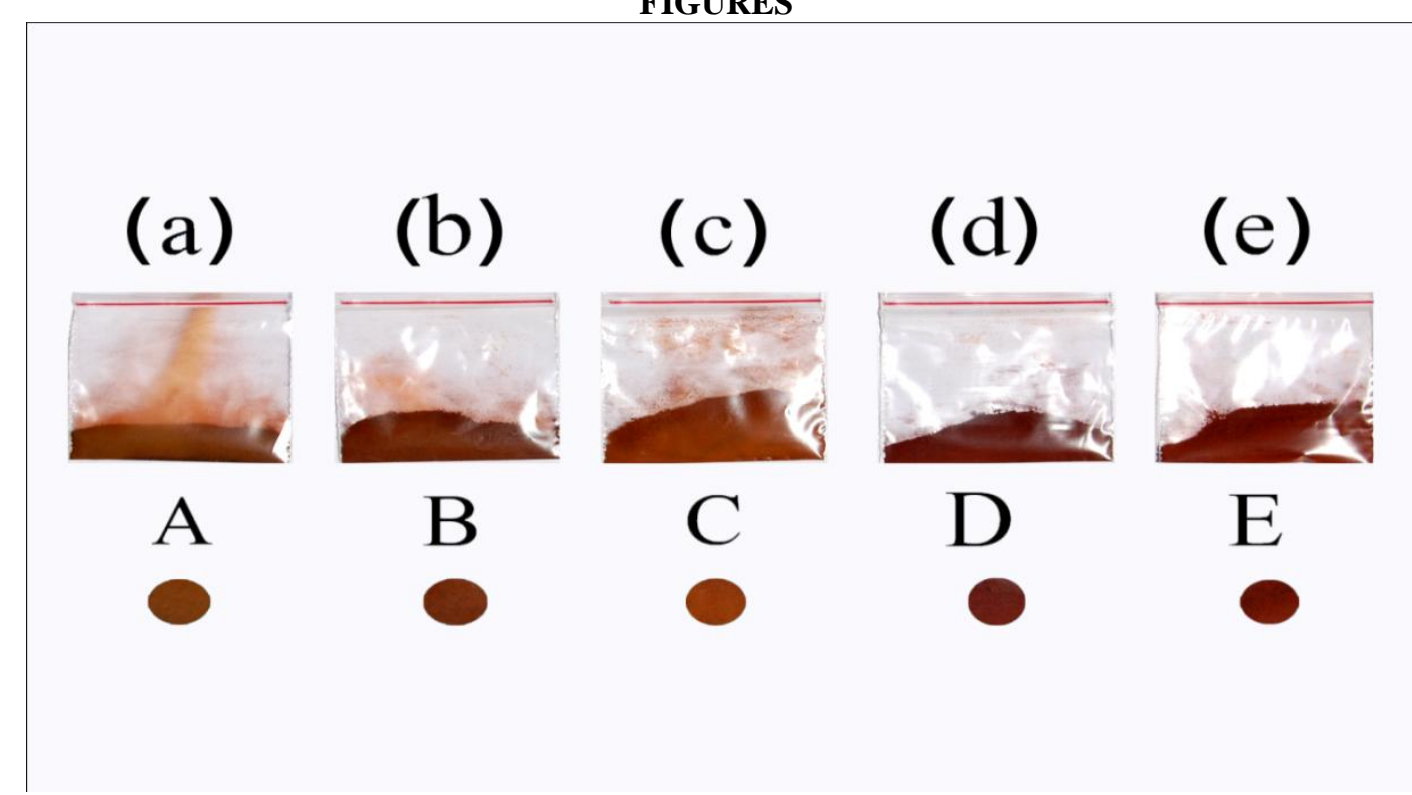

Fig 1: Photograph of samples with pellets : (a) $\rightarrow$ As-prepared, (b) $\rightarrow$ Calcined at $400^{\circ} \mathrm{C}, \quad(c) \rightarrow$ Calcined at $500^{\circ} \mathrm{C},(d) \rightarrow$ Calcined at $600^{\circ} \mathrm{C}$ and $(e) \rightarrow$ Calcined at $700^{\circ} \mathrm{C}$ 


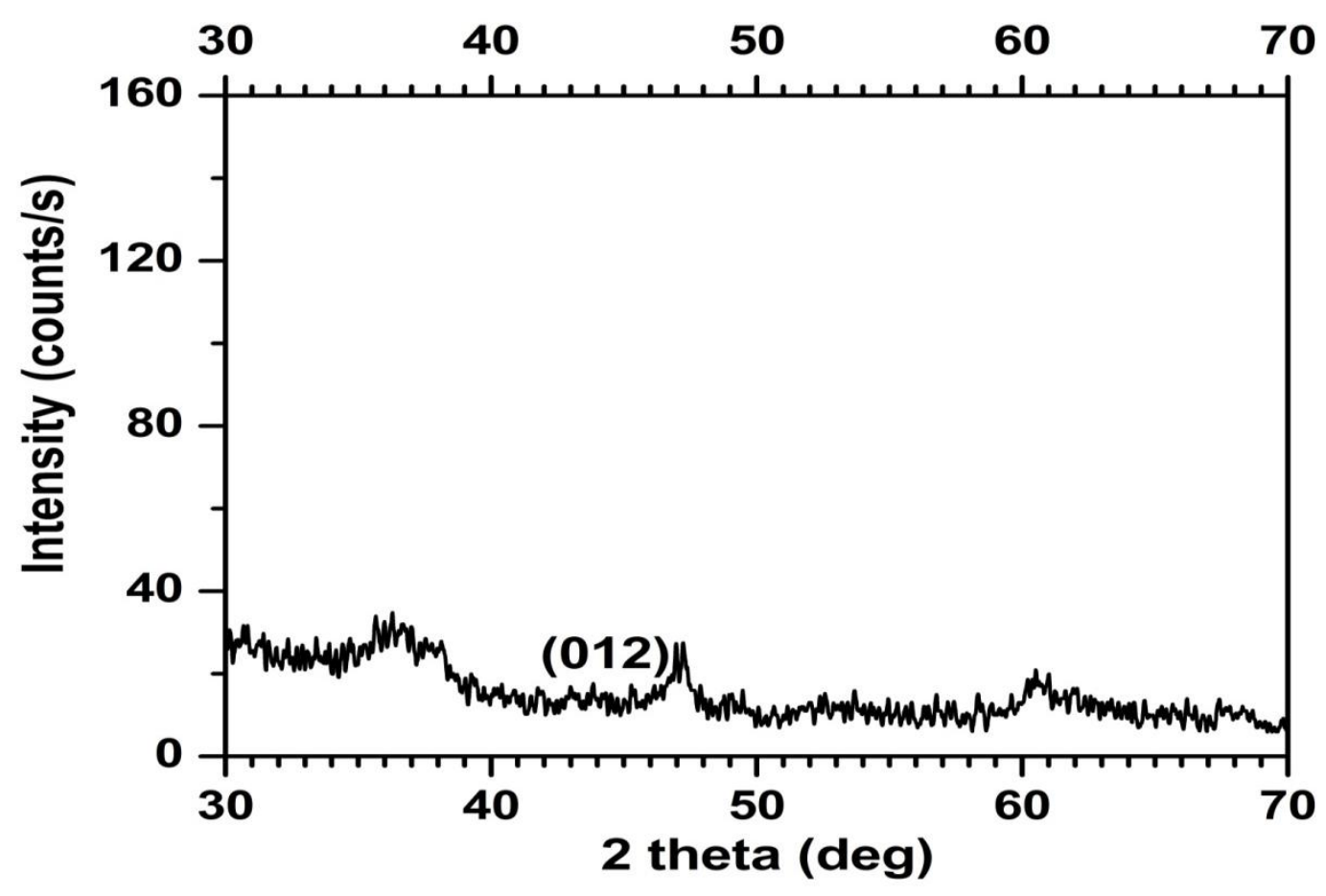

Fig 2: PXRD pattern of the as-prepared sample

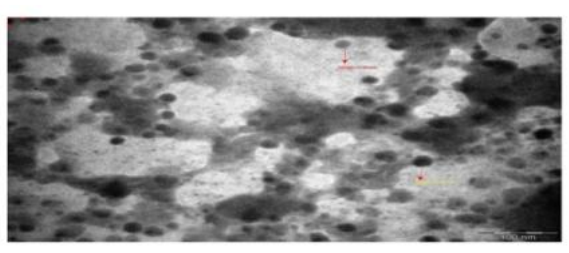

(a)

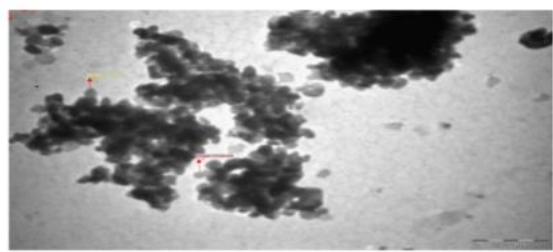

(c)

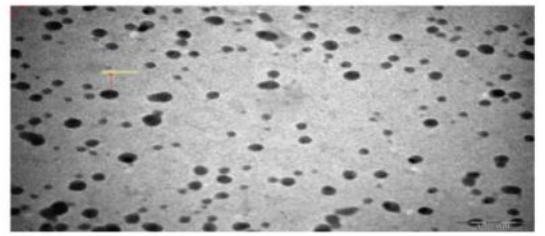

(b)

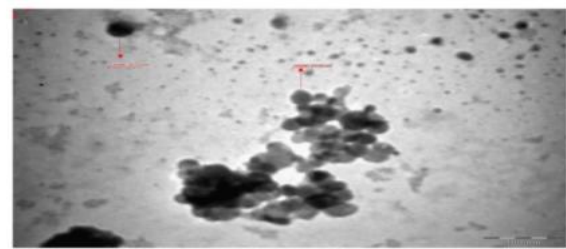

(d)

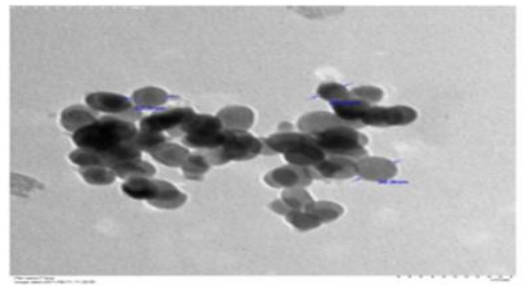

(e)

Fig 3: TEM images : (a) $\rightarrow$ As-prepared, (b) $\rightarrow$ Calcined at $400^{\circ} \mathrm{C}, \quad$ (c) $\rightarrow$ Calcined at $500^{\circ} \mathrm{C},(d) \rightarrow$ Calcined at $600^{\circ} \mathrm{C}$ and $($ e) $\rightarrow$ Calcined at $700^{\circ} \mathrm{C}$ 

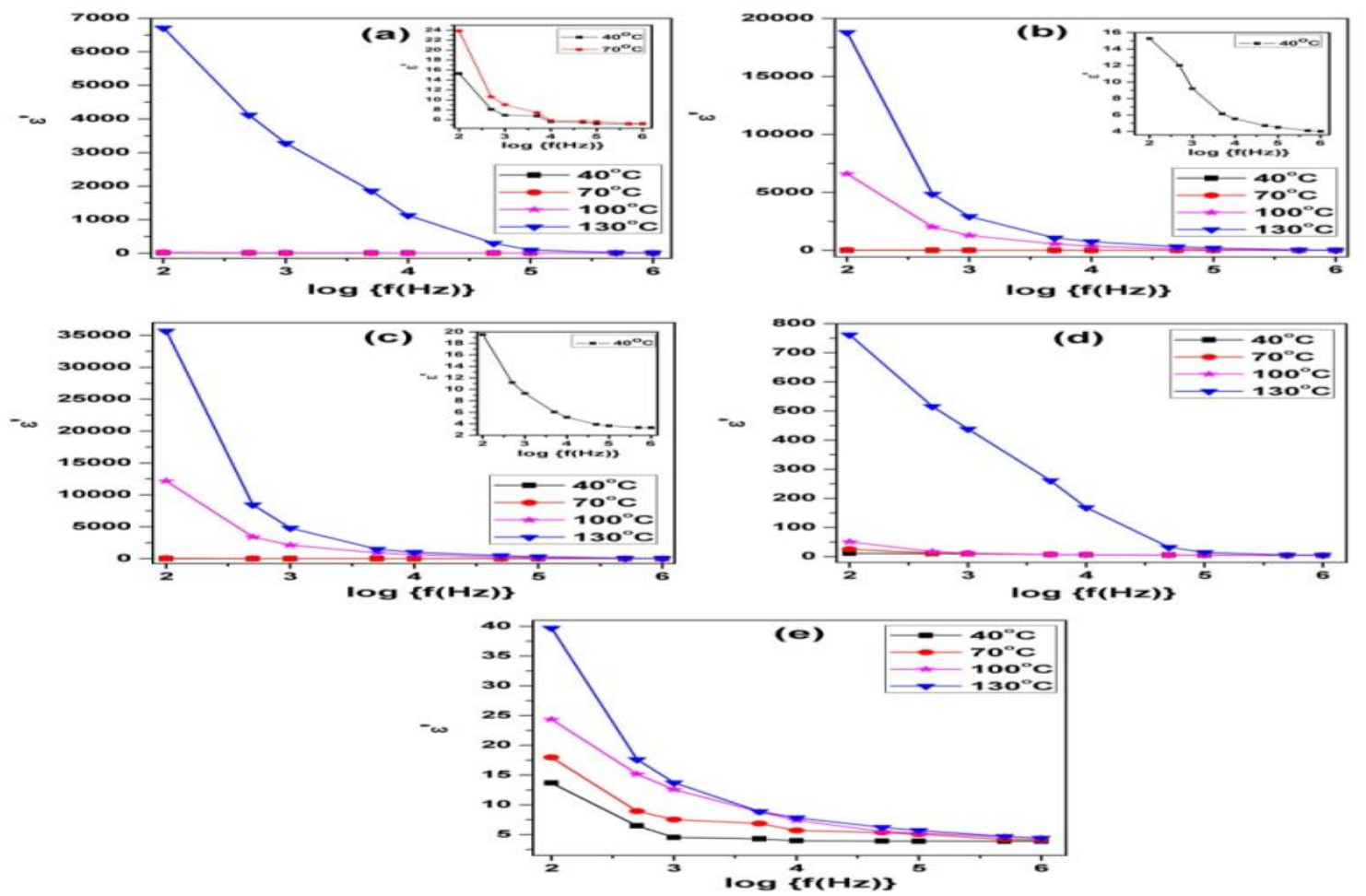

Fig 4: The real parts of dielectric constants $\left(\varepsilon^{\prime}\right):\left(\right.$ a) $\rightarrow$ As-prepared, (b) $\rightarrow$ Calcined at $400^{\circ} \mathrm{C}, \quad(c) \rightarrow$ Calcined at $500^{\circ} \mathrm{C},(d) \rightarrow$ Calcined at $600^{\circ} \mathrm{C}$ and $(\mathrm{e}) \rightarrow$ Calcined at $700^{\circ} \mathrm{C}$ [Unseen plots are shown in insets]
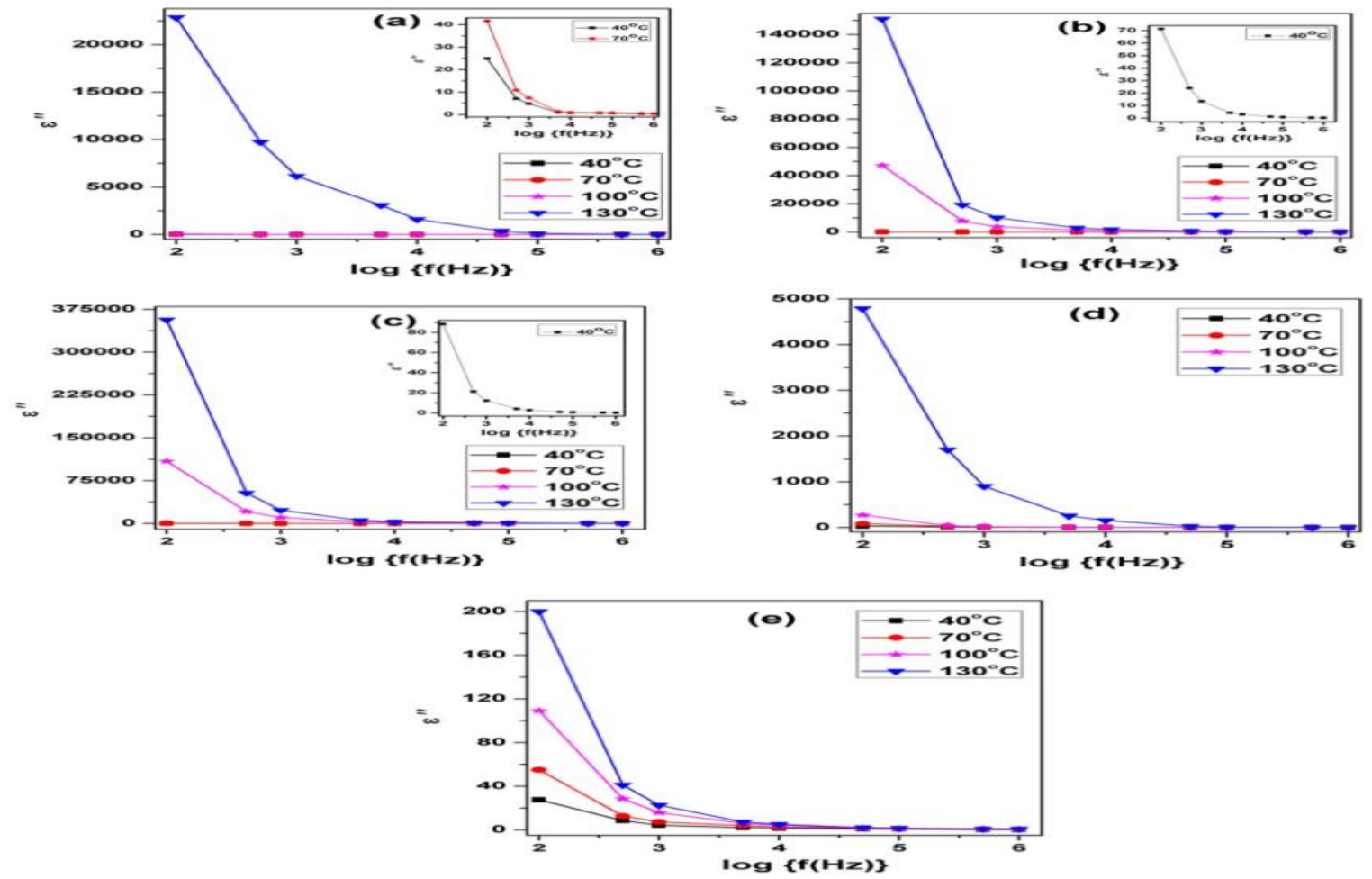

Fig 5: The imaginary parts of dielectric constants $\left(\varepsilon^{\prime \prime}\right):\left(\right.$ a) $\rightarrow$ As-prepared, (b) $\rightarrow$ Calcined at $400^{\circ} \mathrm{C}, \quad\left(\right.$ c) $\rightarrow$ Calcined at $500^{\circ} \mathrm{C},(d)$ $\rightarrow$ Calcined at $600^{\circ} \mathrm{C}$ and $(\mathrm{e}) \rightarrow$ Calcined at $700^{\circ} \mathrm{C}$ [Unseen plots are shown in insets] 


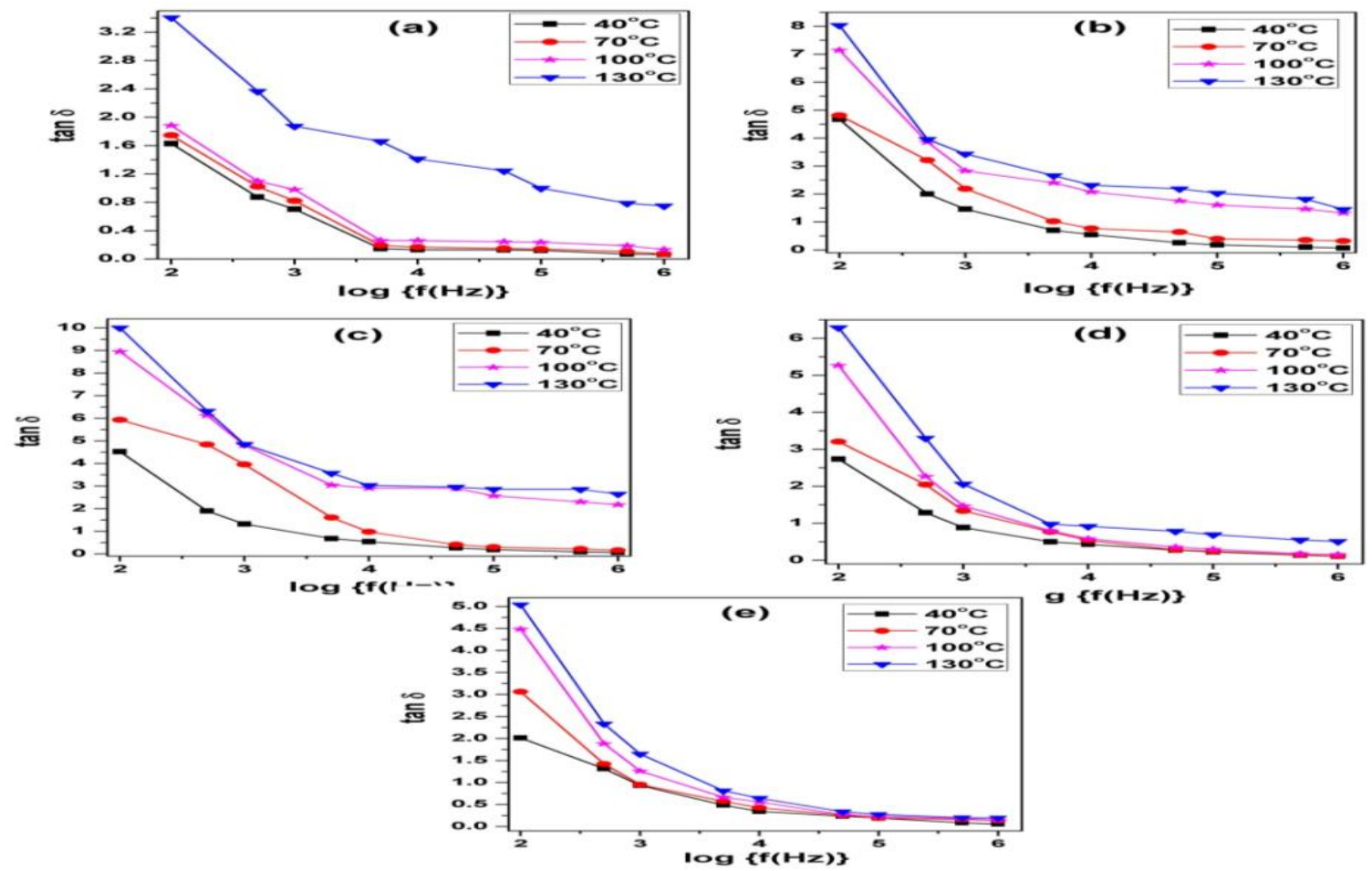

Fig 6: The dielectric loss factors $(\tan \delta):\left(\right.$ a) $\rightarrow$ As-prepared, (b) $\rightarrow$ Calcined at $400^{\circ} \mathrm{C}, \quad\left(\right.$ c) $\rightarrow$ Calcined at $500^{\circ} \mathrm{C},(d) \rightarrow$ Calcined at $600^{\circ} \mathrm{C}$ and $(\mathrm{e}) \rightarrow$ Calcined at $700^{\circ} \mathrm{C}$
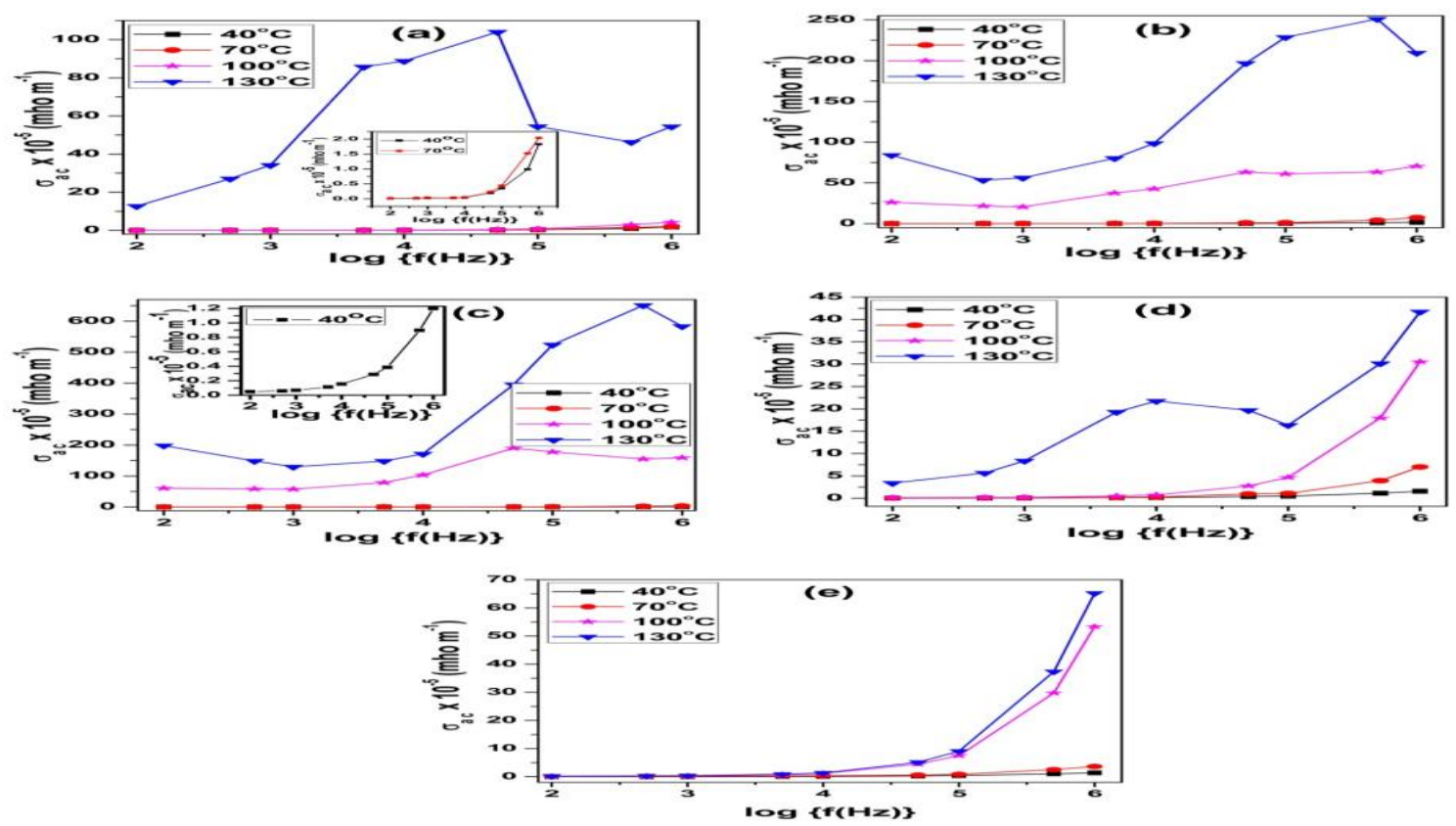

Fig 7: The AC electrical conductivities $\left(\times 10^{-5} \mathrm{mho} \mathrm{m}^{-1}\right)\left(\sigma_{a c}\right):(a) \rightarrow$ As-prepared, (b) $\rightarrow$ Calcined at $400^{\circ} \mathrm{C}, \quad(\mathrm{c}) \rightarrow$ Calcined at $500^{\circ} \mathrm{C},(\mathrm{d}) \rightarrow$ Calcined at $600^{\circ} \mathrm{C}$ and $(\mathrm{e}) \rightarrow$ Calcined at $700^{\circ} \mathrm{C}$ [Unseen plots are shown in insets] 

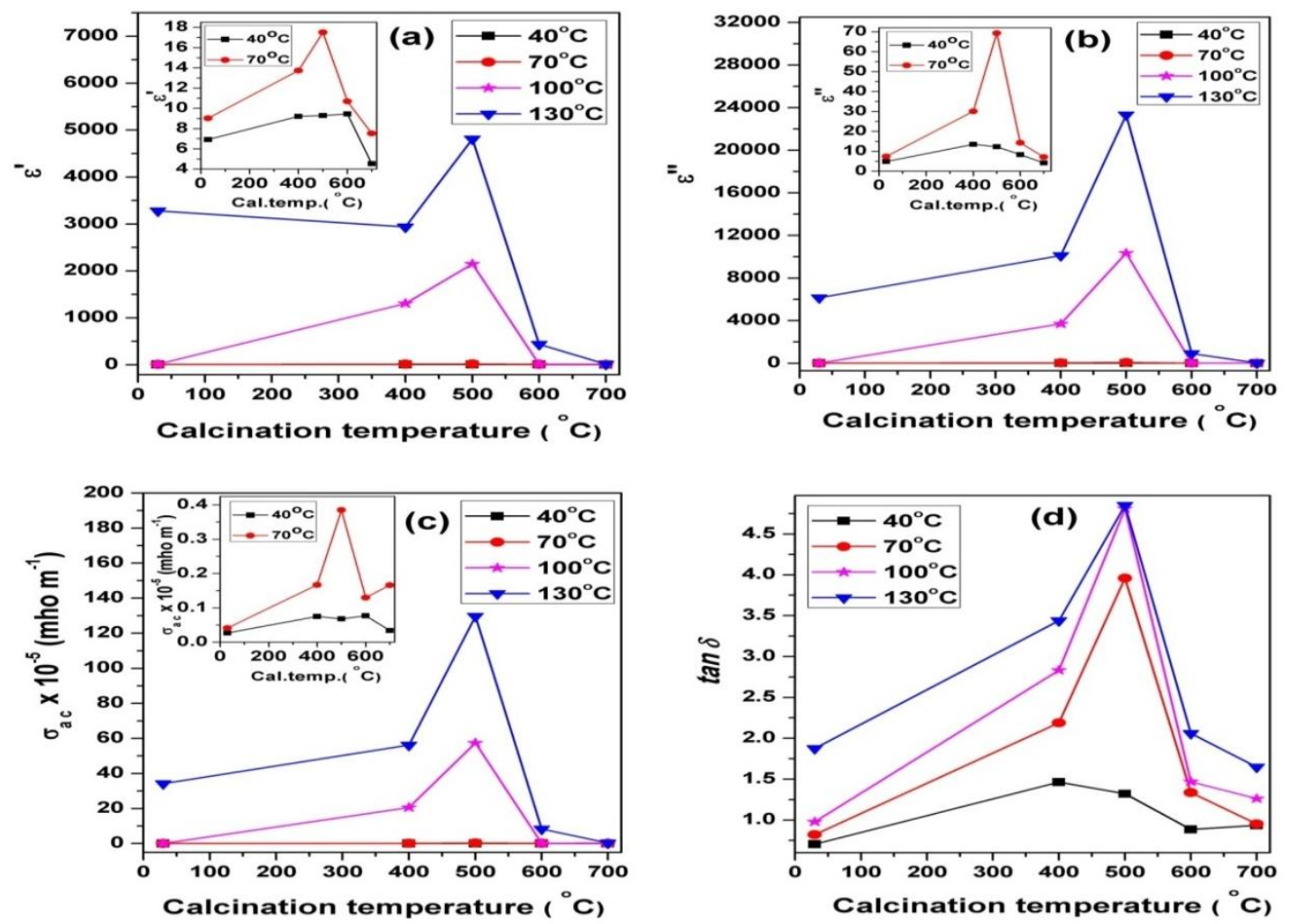

Fig 8: Calcination dependence of of $\varepsilon^{\prime}(\mathrm{a}), \varepsilon^{\prime \prime}(\mathrm{b}) \tan \delta(\mathrm{c})$, and $\sigma_{a c}(\mathrm{~d})$ for $1 \mathrm{KHz}$ frequency at various temperatures [Unseen plots are shown in insets]
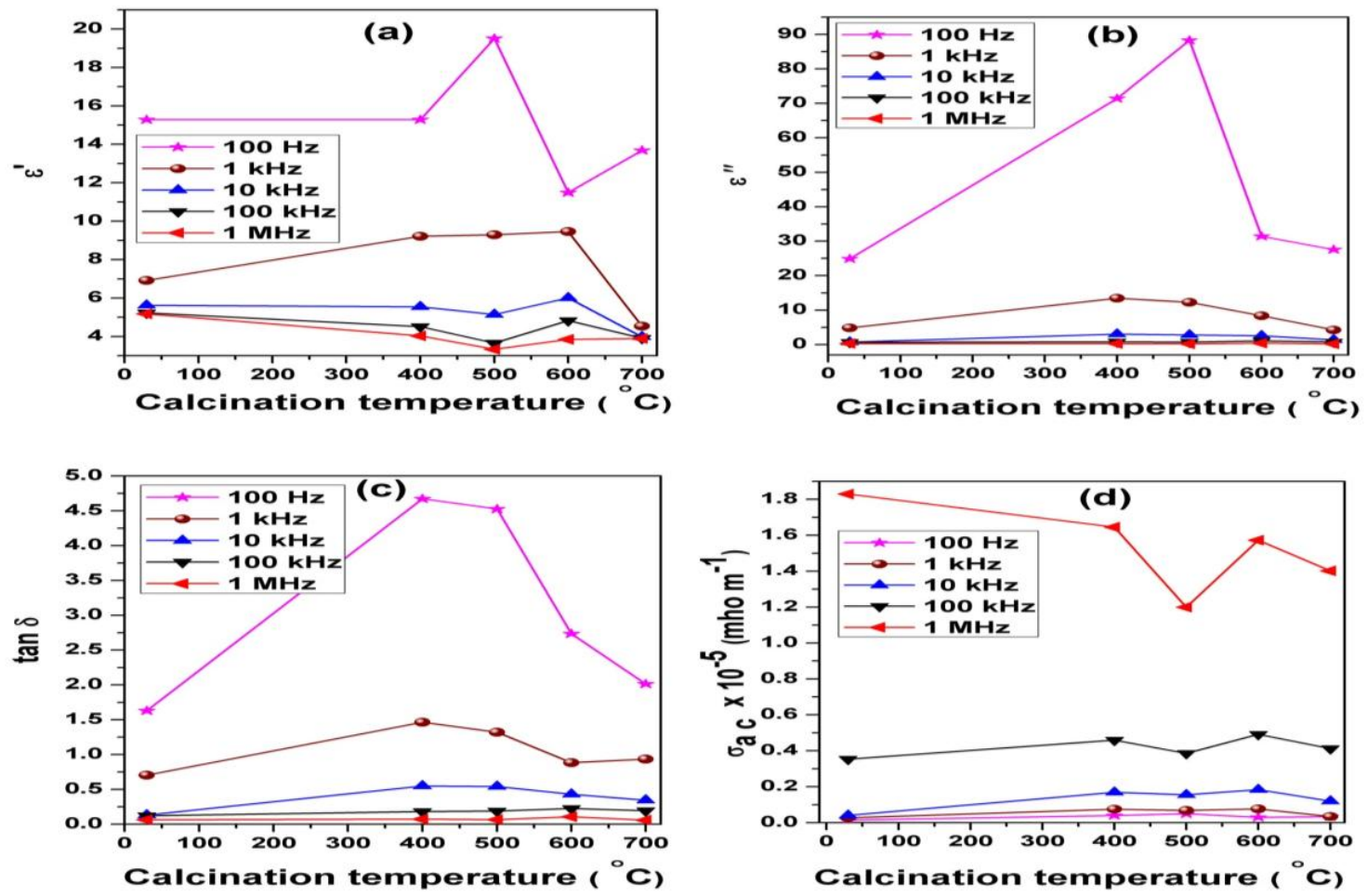

Fig 9: Calcination dependence of $\varepsilon^{\prime}(\mathrm{a}), \varepsilon^{\prime \prime}(\mathrm{b}), \tan \delta(\mathrm{c})$, and $\sigma_{a c}(\mathrm{~d})$ at $40^{\circ} \mathrm{C}$ temperature for various frequencies 

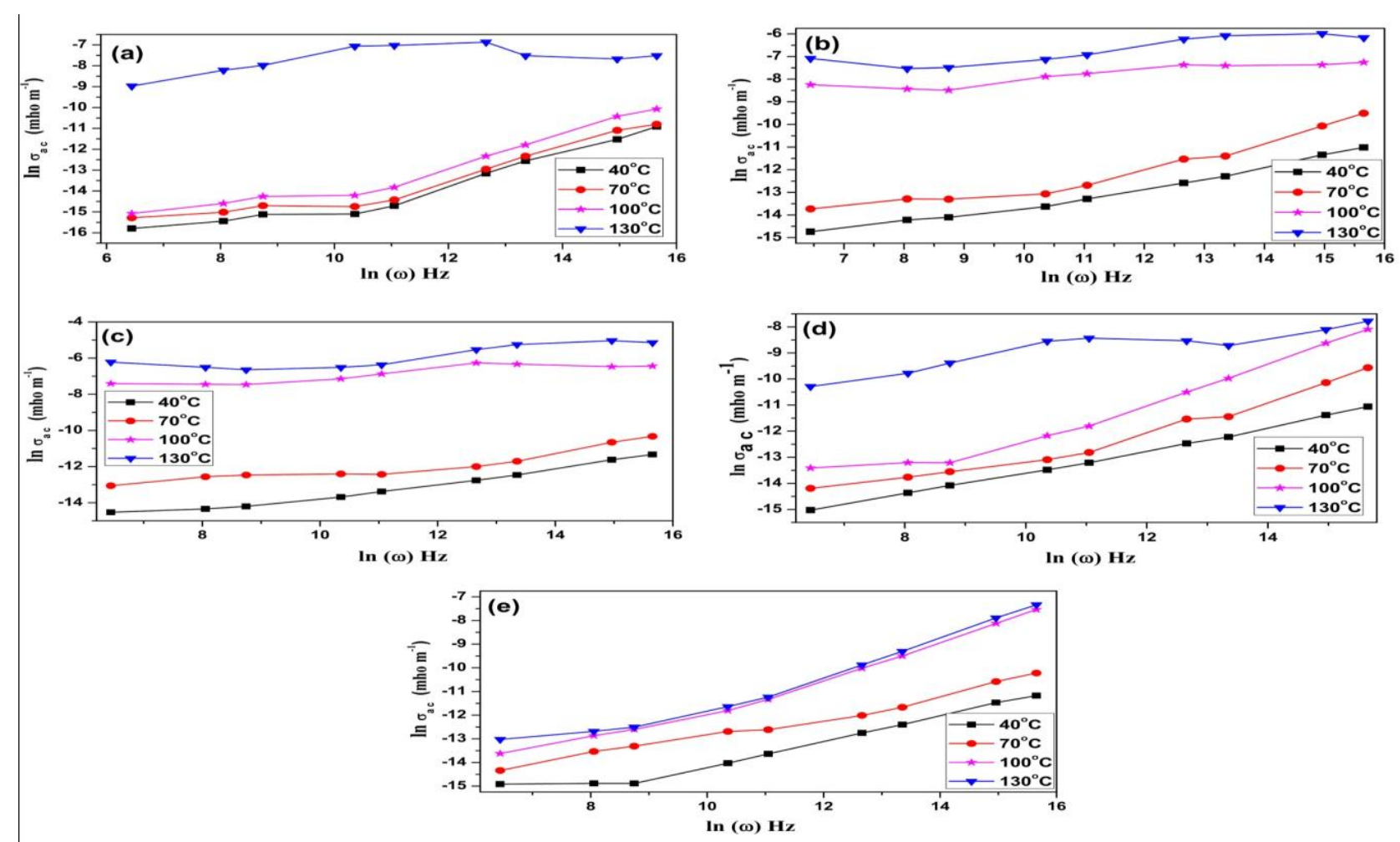

Fig 10: The $\ln \sigma_{\mathrm{ac}}$ vs $\ln \omega$ plots

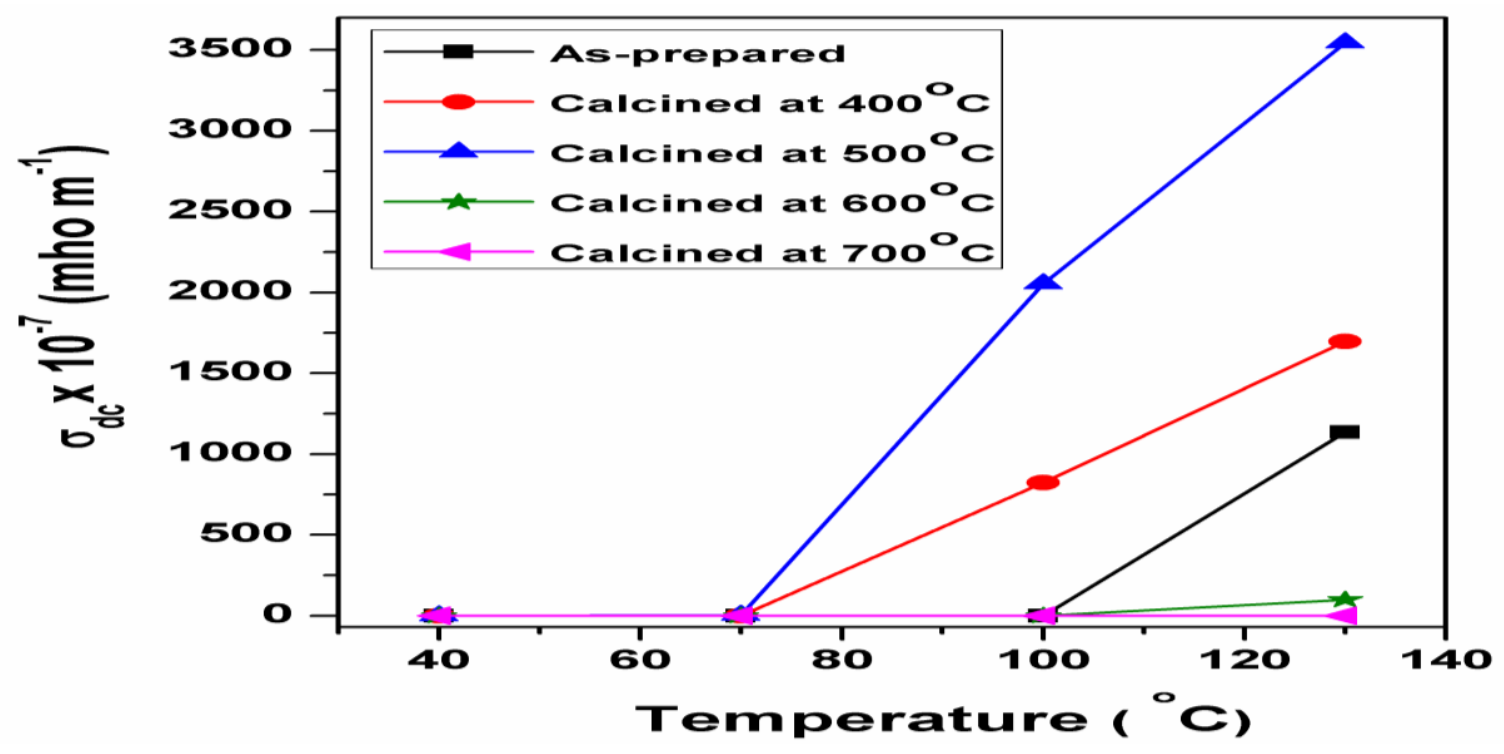

Fig 11: The estimated DC electrical conductivties $\left(\times 10^{-7} \mathrm{mho} \mathrm{m}^{-1}\right)\left(\sigma_{d c}=\mathrm{B}\right)$ 

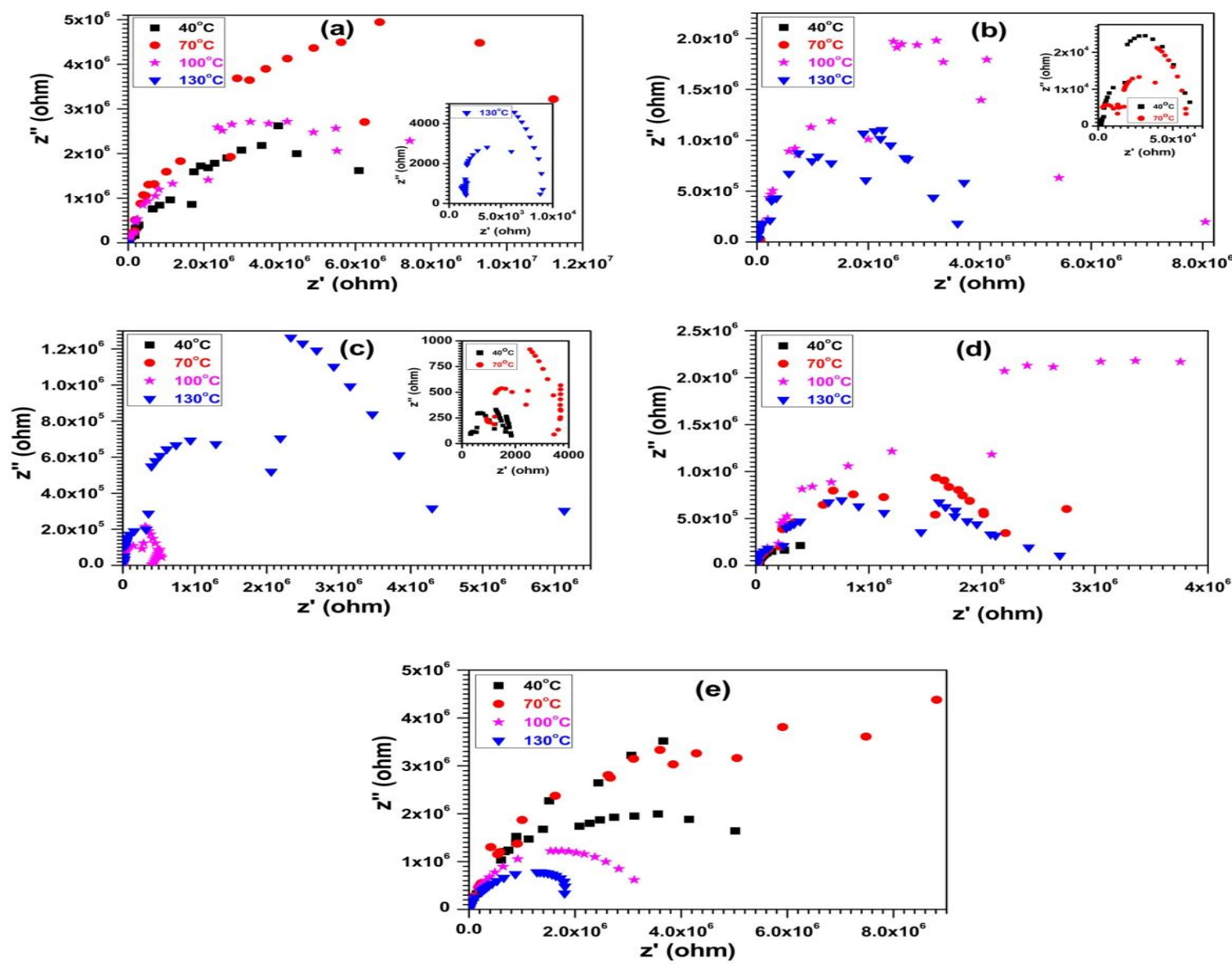

Fig 12: The cole-cole plots : (a) $\rightarrow$ As-prepared, (b) $\rightarrow$ Calcined at $400^{\circ} \mathrm{C}, \quad$ (c) $\rightarrow$ Calcined at $500^{\circ} \mathrm{C},(\mathrm{d}) \rightarrow$ Calcined at $600^{\circ} \mathrm{C}$ and $($ e) $\rightarrow$ Calcined at $700^{\circ} \mathrm{C}$ [Unseen plots are shown in insets]

Table 1: Grain sizes (D), bulk densities $\left(D_{x}\right)$ and densities $\left(D_{o}\right)$ and porosities of pellets

\begin{tabular}{|c|c|c|c|c|c|}
\hline $\mathrm{Fe}_{2} \mathrm{O}_{3}$ sample & $\begin{array}{c}\text { Identified } \\
\text { nanophase }\end{array}$ & $D(\mathrm{~nm})$ & $\begin{array}{c}D_{x} \\
(\mathrm{~g} / \mathrm{cc})\end{array}$ & $\begin{array}{c}D_{o} \\
(\mathrm{~g} / \mathrm{cc})\end{array}$ & $\begin{array}{c}\text { Porosity } \\
(\%)\end{array}$ \\
\hline As-prepared & $\gamma$ & 19 & 4.890 & 1.783 & 63.50 \\
\hline Calcined at $400^{\circ} \mathrm{C}$ & $\varepsilon$ & 24 & 5.022 & 1.649 & 67.16 \\
\hline Calcined at $500^{\circ} \mathrm{C}$ & $\varepsilon+\beta$ & 27 & 5.071 & 1.684 & 66.78 \\
\hline Calcined at $600^{\circ} \mathrm{C}$ & $\beta+\alpha$ & 29 & 5.120 & 1.833 & 64.19 \\
\hline Calcined at $700^{\circ} \mathrm{C}$ & $\alpha$ & 33 & 5.270 & 2.328 & 55.82 \\
\hline
\end{tabular}


Table 2: $\varepsilon^{\prime}, \varepsilon^{\prime \prime}$, tan $\delta$, and $\sigma_{a c}$ values for $1 \mathrm{kHz}$ frequency, and $\sigma_{d c}$ values at $40^{\circ} \mathrm{C} \mathrm{h}$ and estimated $a_{B}$, and $\mathrm{D} / a_{B}$ values

\begin{tabular}{|c|c|c|c|c|c|c|c|c|}
\hline $\mathrm{Fe}_{2} \mathrm{O}_{3}$ sample & $\begin{array}{c}\text { Identified } \\
\text { nanophase }\end{array}$ & $\varepsilon^{\prime}$ & $\varepsilon^{\prime \prime}$ & $\tan \delta$ & $\begin{array}{c}\sigma_{a c} \\
\left(\mathrm{x} 10^{-5}\right. \\
\mathrm{mho} / \mathrm{m})\end{array}$ & $\begin{array}{c}\sigma_{d c} \\
\left(\mathrm{x} 10^{-7}\right. \\
\mathrm{mho} / \mathrm{m})\end{array}$ & $\begin{array}{c}a_{B} \\
(\mathrm{~nm})\end{array}$ & $D / a_{B}$ \\
\hline As-prepared & $\gamma$ & 6.919 & 4.869 & 0.704 & 0.027 & 0.020 & 41.8 & 0.307 \\
\hline Calcined at $400^{\circ} \mathrm{C}$ & $\varepsilon$ & 9.214 & 13.483 & 1.463 & 0.075 & 0.225 & 54.8 & 0.438 \\
\hline Calcined at $500^{\circ} \mathrm{C}$ & $\varepsilon+\beta$ & 9.292 & 12.271 & 1.321 & 0.068 & 0.319 & 55.3 & 0.488 \\
\hline Calcined at $600^{\circ} \mathrm{C}$ & $\beta+\alpha$ & 9.456 & 8.350 & 0.883 & 0.077 & 0.179 & 56.3 & 0.515 \\
\hline Calcined at $700^{\circ} \mathrm{C}$ & $\alpha$ & 4.536 & 4.242 & 0.935 & 0.034 & 0.096 & 27.0 & 1.222 \\
\hline
\end{tabular}

